\title{
PROPOSTAS PEDAGÓGICAS DE OSCAR LORENZO FERNANDEZ PARA O ENSINO DA MÚSICA NAS ESCOLAS PÚBLICAS BRASILEIRAS (1930-1931)
}

DOI: http://dx.doi.org/10.1590/2236-3459/61437

\author{
Ednardo Monteiro Gonzaga do Monti \\ Universidade Federal do Piauí, Brasil.
}

$\cos 8$

\begin{abstract}
Resumo
Este estudo tem como objetivo analisar a proposta pedagógica de Lorenzo Fernandez, músico nacionalista que atuou no Instituto Nacional de Música e na Universidade do Distrito Federal UDF -, instituições sediadas na cidade do Rio de Janeiro, então capital da República. A principal fonte documental mobilizada nesta investigação é o periódico Illustração Musical (1930-1931). Como resultado percebe-se que, para Lorenzo Fernandez, a base do ensino da música nas escolas públicas era a formação de professores por meio de cursos especializados com ênfases musicais e pedagógicas consistentes, uma proposta que dependia dos investimentos do governo brasileiro vigente no período em questão.

Palavras-chave: história da educação, educação musical, Oscar Lorenzo Fernandez, revista Illustração Musical.

\section{EDUCATIONAL PROPOSALS BY OSCAR LORENZO FERNANDEZ FOR MUSIC EDUCATION IN BRAZILIAN PUBLIC SCHOOLS (1930-1931)}

\begin{abstract}
This study aims to analyze the pedagogical proposal by Oscar Lorenzo Fernandez, a nationalistic musician who was based at the Instituto Nacional de Música and the Universidade do Distrito Federal - UDF - in Rio de Janeiro, capital city of the Republic of that time. Research for this project is fundamentally based on the magazine Illustração Musical (1930-1931). As a result of this project, it would seem that Lorenzo Fernandez proposed that music education in public schools be supported by specialized teacher training courses that boasted a consistent musical and pedagogical emphasis, a proposal that depended on the then Brazilian government's investments. Key-words: history of education, musical education, Oscar Lorenzo Fernandez, magazine Illustração Musical.
\end{abstract}




\section{PROPUESTAS PEDAGÓGICAS DE OSCAR LORENZO FERNANDEZ DE LA EDUCACIÓN MUSICAL EN LAS ESCUELAS PÚBLICAS DE BRASIL (1930-1931)}

\section{Resumen}

Este artículo tiene como objetivo analizar la propuesta pedagógica de Lorenzo Fernandez, músico nacionalista que actuó en el Instituto Nacional de Música y en la Universidad do Distrito Federal UDF -, instituciones situadas en la ciudad de Rio de Janeiro, Capital de la Republica en ese tiempo. La principal fuente documental usada en esta investigación es el periódico llustração Musical (1930-1931). Como resultado se nota que para Lorenzo Fernandez la base de la enseñanza de la música en las escuelas públicas era la formación de los profesores por medio de cursos especializados con énfasis musicales y pedagógicas consistentes, una propuesta que dependía de las inversiones del gobierno brasileño vigente en ese período.

Palabras-clave: historia de la educación, educación musical, Oscar Lorenzo Fernandez, revista Ilustração Musical.

\section{PROJET PEDAGOGIQUE DE OSCAR LORENZO FERNANDEZ SUR L'EDUCATION MUSICALE DANS LES ECOLES PUBLIQUES DU BRESIL (1930-1931)}

\section{Résumé}

Cet article a pour objectif d'analyser le projet pédagogique de Lorenzo Fernández, musicien nationaliste qui a joué à l'Institut National de Musique et à l'Université du District Fédéral - UDF -, institutions situées dans la ville de Rio de janeiro, Capitale de la république à cette époque. La principale source documentaire utilisée dans cette recherche est le journal Illustration Musicale (1930-1931). Par conséquent, on remarque que selon Lorenzo Fernández l'enseignement de la musique dans les écoles publiques repose sur la formation des professeurs par le biais de cours spécialisés mettant l'accent sur l'enseignement musical et une pédagogie cohérente. Ce projet dépendait des investissements du gouvernement brésilien en vigueur à cette période.

Mots-clé: histoire de l'éducation, éducation musicale, Oscar Lorenzo Fernández, magazine Illustration Musicale. 


\section{Introdução}

N este texto são apresentadas reflexões sobre os ideais do músico, poeta e educador Oscar Lorenzo Fernandez, ideias publicadas em forma de artigo na revista pedagógica e musical chamada Illustração Musical. O músico nacionalista foi diretor desse periódico, por isto é possível considerar que os textos do compositor veiculados pelo impresso representam partes significativas do seu pensamento musical e pedagógico, ideais que transitavam pelas instituições artísticas e educacionais nos primeiros anos da Era Vargas. Como escreveu no primeiro editorial, sua proposta para a revista era "exclusivamente informativa educadora" (Fernandez, 1930, p. 1). Escrevo com outras palavras: a revista de grande circulação nacional era um canal para a divulgação do que era realizado e pensado sobre o ensino da música no período em questão.

Com Denice Barbara Catani (1996) compreendo que os periódicos são entradas para investigações no campo da História da Educação, porque as "revistas especializadas, no Brasil e em outros países, de modo geral, constituem uma instância privilegiada para a apreensão dos modelos de funcionamento do campo educacional" ( $p$. 117). Isso acontece pelo fato de que estes impressos fomentaram a circularidade de informações referentes "ao trabalho pedagógico e o aperfeiçoamento das práticas docentes, o ensino específico das disciplinas, a organização dos sistemas, as reivindicações da categoria do magistério" (p. 117), bem como outros diferentes temas que surgem nesse campo do saber. Ainda com as ideias de Catani (1996), acredito que "é possível analisar a participação dos agentes produtores do periódico na organização do sistema de ensino e na elaboração dos discursos que visam a instaurar as práticas" ( $p$. 117) que podem configurar modelos pedagógicos de um período.

O primeiro número da revista Illustração Musical foi publicado em agosto de 1930 e o redator-chefe era Augusto F. Lopez Gonçalves. No Brasil, além dos participantes da capital da República, o informativo contava com colaboradores de São Paulo, Belo Horizonte, Manaus, Belém, Paraíba, Recife, Salvador, Curitiba, Porto Alegre, Pelotas e Rio Grande. Também colaboravam com o periódico pessoas dos seguintes países: Alemanha, Espanha, França, Estados Unidos, Itália e Portugal. Havia representantes do impresso musical em Buenos Aires (Argentina), Santiago (Chile), Havana (Cuba), Nova Iorque (EUA), México, Assunção (Paraguai) e Lima (Peru). Estes dados do expediente do primeiro número do periódico indicam que a revista estava vinculada às atividades pedagógicas e musicais dos vários Estados brasileiros e, igualmente, com contatos estabelecidos em diferentes países.

Este mesmo expediente também sinaliza que a revista organizada por Lorenzo agregava as instituições que se propunham a transitar no campo da música e da educação, pois era um impresso oficial das seguintes instituições: Associação Brasileira de Música, Escola de Música Figueiredo, Escola e Grêmio Arcangelo Corelli do Rio de Janeiro, Instituto de Música da Bahia, Instituto Carlos Gomes de Belém e Conservatório de Música de Niterói.

Destaco a importância destas reflexões sobre os ideais do compositor pelo fato de realçar a própria trajetória pedagógica de Lorenzo Fernandez, fundador de uma tradicional escola de música do Brasil, o Conservatório Brasileiro de Música. Além disso, o músico nacionalista atuou como catedrático em outras importantes instituições de 
ensino de música do Brasil, na formação de jovens voltados para a performance musical no Instituto Nacional de Música, hoje Escola de Música da Universidade do Rio de Janeiro, como também no preparo daqueles que almejavam ser professores da disciplina Música e Canto Orfeônico, que estudaram na Universidade do Distrito Federal - UDF/RJ e no Conservatório Nacional de Canto Orfeônico, todos no Rio de Janeiro, então capital da República.

Percebe-se, assim, que o compositor e poeta Oscar Lorenzo Fernandez não trabalhou diretamente com as turmas de crianças da escola primária, mas dedicou parte de sua trajetória preparando musical e pedagogicamente adolescentes e jovens que passaram pelas escolas de música do Distrito Federal, além de contribuir planejando e pensando a estrutura da educação musical no Brasil.

$\mathrm{Na}$ década de 1930 o compositor Lorenzo Fernandez era uma personalidade bastante respeitada no meio musical, pois já se destacava desde 1922, quando conquistou o primeiro lugar em três categorias do Concurso Nacional de Composição, com as peças: Noturno e Arabesco, para piano, e Cisne, para canto e piano. O evento era promovido no Distrito Federal pela Sociedade de Cultura Musical do Rio de Janeiro. Foi nesse período também que o artista estabeleceu amizade com o modernista José Pereira Graça Aranha, escritor que tornou o músico um assíduo apreciador da obra de Villa-Lobos na Semana de Arte Moderna de 1922 (Corrêa, 1992).

Sua carreira musical era bastante vinculada às personalidades do movimento modernista. Mario de Andrade o destacou como um dos maiores músicos do Brasil. Em 1934, no principal evento do aniversário da cidade de São Paulo, aconteceu um concerto realizado com obras sinfônicas e liedees de Lorenzo Fernandez. Sobre esta comemoração, no jornal Diário de São Paulo ${ }^{1}$, o poeta e musicólogo paulistano escreveu o seguinte:

Lorenzo Fernandez é, no momento, uma das figuras mais altas da música brasileira. No seu grupo de geração, já caracteristicamente especificador da musicalidade artística nacional, grupo que contém ainda Villa-Lobos e Luciano Gallet, ele representa, mais que os outros o conhecimento técnico, o lado por assim dizer "acadêmico", desde que se tire desta palavra a significação odiosa. De fato, Lorenzo Fernandez joga no certo, e ainda as suas peças sinfônicas, de ontem, só agora executadas aqui, provaram isso bem. Tristão de Ataíde teve uma feita, pra caracterizar dois escritores, uma imagem feliz. Disse que ia botar os seus trilhos nas terras em que já havia cidades, ao passo que o outro botava os seus em paragens desertas, na esperança de cidades futuras. Lorenzo Fernandes é dos que gostam de servir a cidades já existentes. A sua criação não tem aquelas invenções em paragens desertas, na esperança de cidades futuras. Lorenzo, a sua criação não tem aquelas invenções arroubadas com que Villa-Lobos dispensa a técnica pra criar uma possível "técnica" que só a boniteza da obra parece justificar. Nem a inquietação tormentosa, o excesso de inteligência crítica que perturbava a liberdade criadora de Luciano Gallet. Lorenzo Fernandez muito embora usando as conquistas da técnica musical do nosso tempo, se compraz em adaptá-la com segurança, onde elas sejam duma lógica imprescindível, como que indispensáveis. (Andrade, 1943, p. 7)

\footnotetext{
${ }^{1}$ ANDRADE, Mário de. Lourenço Fernandez. Diário de são Paulo, 26 de janeiro de 1934. (Acervo Histórico da Biblioteca do Conservatório Brasileiro de Música - Centro Universitário) 
Após a Semana de Arte Moderna, em 17 de julho de 1923, Oscar Lorenzo Fernandez foi nomeado professor substituto de Harmonia Superior para atender a demanda que surgiu pelo impedimento da atuação do seu professor. O catedrático Frederico Nascimento ficou afastado das atividades docentes por motivo de doença. Assim, o compositor nacionalista tornou-se o mais jovem professor do Instituto Nacional de Música, mesmo antes de terminar o curso de Contraponto e Fuga, em 18 de dezembro de 1923 (Corrêa, 1992).

Nessa instituição de ensino começou a estudar, em 1918, com o professor Frederico Nascimento, que se tornou seu "mentor" artístico (Corrêa, 1992) e que lhe apresentou a Alberto Nepomuceno, compositor considerado o pai da música nacionalista erudita no Brasil, considerado um mestre no campo da estética nativista, influência que perpassa as produções de Lorenzo Fernandez (Pádua, 2009). Porém, o compositor somente tomou posse como catedrático de Contraponto e Fuga em 1943, quando o Instituto Nacional de Música já se chamava Escola Nacional de Música da Universidade do Brasil.

Vale ressaltar que os estudos existentes sobre o músico apenas mencionam sua atuação pedagógica, ou seja, não focalizam e analisam esse aspecto da sua identidade e produção. Não há artigos, dissertações e teses que abordem as ideias, os feitos, as conquistas e os projetos de Lorenzo Fernandez como educador. Seu acervo pessoal está no Conservatório Brasileiro de Música - Centro Universitário, tratado e disponível, porém os investigadores abordam especificamente a sua produção musical. Não há investigações acadêmicas sobre Lorenzo Fernandez numa perspectiva da História da Educação Musical ou da História da Educação. Não há trabalhos que abordem as suas produções direcionadas à formação de músicos e à sua atuação na formação de professores de música na Escola Nacional de Música, na Universidade do Distrito Federal, no Conservatório Brasileiro de Música e no Conservatório Nacional de Canto Orfeônico.

Sendo assim, entende-se a revista Illustração Musical como um relevante documento para a História da Educação e as ideais de Lorenzo Fernandez como pensamentos bastante significativos no processo de consolidação da música na escola. Para nortear este texto, parto dos seguintes questionamentos: quais eram as propostas do músico brasileiro para a consolidação da música na escola brasileira na década de 1930 ? Como e onde estas ideias se concretizaram? Com quem se articulou para alcançar seus objetivos?

Para dar contornos ao texto, organizei-o em duas seções sobre as ideias de Lorenzo Fernandez na revista Illustração Musical. Na primeira parte preocupo-me em descrever e analisar o artigo Bases para a organização da música no Brazil, texto publicado na revista número 4, de novembro de 1930, que expressa os pensamentos do artista sobre a estrutura da educação musical em âmbito nacional, desde os primeiros anos de escolaridade até os cursos em nível superior. Depois, na segunda seção, centro as atenções no segundo artigo do compositor que está na revista número 3, última publicação do periódico, de março de 1931, no qual aborda as ideias pedagógicas para a prática do canto coral nas escolas regulares. 


\section{Bases para a organização da música no Brasil}

Sérgio Nepomuceno Alvim Corrêa afirma, no catálogo geral de Lorenzo Fernandez, que o compositor já antecipava a reforma da educação musical implantada por Heitor Villa-Lobos, o músico que foi responsável pela gestão da disciplina Música e Canto Orfeônico nas escolas brasileiras. A justificativa de Corrêa é embasada no fato dos textos de Oscar antecederem as propostas de Villa-Lobos, ou seja, antes deste implantar o Canto Orfeônico como uma disciplina obrigatória no Brasil, Oscar já havia apresentado para as autoridades políticas e culturais do "governo um vasto plano de mudanças e de incremento, para melhor aproveitamento do ensino musical" (Corrêa, 1992, p. 22), principalmente por meio "da criação de mais conservatórios e de novos métodos de ensino, além de apresentar uma série de requisitos para a implantação do canto coral" ( $p$. 22) nas escolas brasileiras.

É bem verdade que as Bases para a organização da música no Brazil - de Oscar é um texto que precede os escritos de Villa-Lobos sobre a educação musical no Brasil. Por meio deste artigo Lorenzo Fernandez apresenta a transformação do Instituto Nacional de Música na Escola Nacional de Música, elevando os cursos da instituição ao nível superior, como também propõe a criação de carreiras musicais pedagógicas, direcionadas às classes com grande número de alunos, isso porque não havia a formação oficial para docentes de música para as escolas de formação geral. O Instituto de Música formava seus alunos para carreira musical e para atuar nos conservatórios ou em outras escolas específicas da área musical. Nesse período, com a proposta de crescimento e ampliação da escola pública, havia a necessidade de professores preparados para trabalhar com turmas de alunos sem formação musical específica.

Nessa proposta de estrutura, escrita por Lorenzo Fernandes, havia articulações dos cursos pedagógicos com as escolas públicas, com vistas à implantação do canto coral nas unidades escolares e à criação de um curso livre para crianças no Instituto Nacional de Música. O músico nacionalista não utilizou o nome canto orfeônico para estas atividades pedagógicas. $O$ intelectual também sugeriu a transformação do Theatro Municipal do Rio de Janeiro num teatro nacional para estágios dos alunos de performance dessa escola superior de música. Entretanto, seu projeto não se efetivou no âmbito da instituição que foi iniciada na casa do padre José Maurício Nunes Garcia, atual Escola de Música da Universidade Federal do Rio de Janeiro - EM/UFRJ.

Depois, em 1937, houve a transformação do Instituto Nacional de Música na Escola Nacional de Música, que ficou vinculada à Universidade do Brasil. Porém, antes dessa mudança, ocorreu a criação da Universidade do Distrito Federal - UDF -, instituída pelo decreto municipal n. 5.513, em abril de 1935, instituição na qual surgiu o primeiro curso superior de música do Brasil. A UDF foi criada por Anísio Teixeira e o Instituto de Educação fez parte da vida curta desse projeto do governo do Distrito Federal (Mendonça, 2002). Villa-Lobos foi o nomeado pelos gestores da prefeitura do Rio de Janeiro para estruturar e dirigir o Curso de Formação de Professores com Especialização em Música e Canto Orfeônico (Villa-Lobos, 1946).

Villa-Lobos utilizou parcialmente a estrutura proposta por Lorenzo Fernandez no artigo Bases para a organização da música no Brazil, publicado na Revista Illustração Musical. Entretanto, destaco que isso aconteceu de comum acordo entre os dois músicos, pois Oscar fez parte do corpo docente em todo período de existência do curso de Música 
e Canto Orfeônico da UDF. Também é interessante pensar que o Instituto de Educação do Rio de Janeiro era a instituição que possuía as melhores condições para a articulação das pesquisas no campo da educação musical e dos estágios dos professores de música em formação, pois lá havia cursos da escola primária ao ensino superior, possibilidade que Lorenzo Fernandez não pensou ou deixou registrado nos seus artigos (Monti, 2015).

A utilização do projeto de Lorenzo Fernandez não foi integral. Reafirmo como parcial porque a parte voltada para os alunos dos cursos de performance, que seria articulada com um teatro nacional, não foi implantada na Universidade do Distrito Federal. $O$ Instituto de Educação do Rio de Janeiro, vinculado à UDF, possuía uma acentuada vocação para a formação de professores e, ao que parece, a música foi incluída porque faltavam professores de Música e Canto Orfeônico nas escolas públicas e privadas.

A transformação do Instituto Nacional de Música na Escola de Música ocorreu na gestão de Sá Pereira, em 1937, portanto, dois anos após a criação do curso de Formação de Professor Especializado de Música e Canto Orfeônico do Instituto de Educação do Rio de Janeiro e sete anos depois da publicação de Lorenzo na revista Illustração Musical. A orquestra, para articulação dos alunos com formação em performance com a vida profissional, aconteceu somente na década de 1970, na administração de Baptista Siqueira, quando a Escola de Música fez um novo regimento, que organizou a administração acadêmica em sete departamentos. A Orquestra Sinfônica da instituição foi reformulada, fazendo os alunos da graduação se tornassem a principal base do quadro de instrumentistas (Siqueira, 1972).

Outra ideia de Lorenzo Fernandez não implantada na década de 1930 foi a criação dos conservatórios equiparados à Escola Nacional de Música nas principais capitais do Brasil, como também a transformação das normas das instituições de música já existentes para equiparação. Somente em 1942, quando o Conservatório Nacional de Canto Orfeônico - CNCO - foi instituído é que houve tal possibilidade. O estabelecimento especializado na formação de professores de música para atuação nas escolas era uma instituição modelo, padrão a ser seguido por outros conservatórios com a mesma finalidade, conforme o decreto-lei n. 4.993, de 26 de novembro de 1942, que institui o CNCO. A liderança da instituição foi de força tamanha que chegou ao ponto que a formação de todos os educadores musicais que ministravam a disciplina Música e Canto Orfeônico em escolas dos diferentes Estados brasileiros deveriam ter seus diplomas equiparados ou reconhecidos, por meio de inspeção federal, aos certificados do CNCO (Monti, 2015).

Considero importante ressaltar que o Conservatório Nacional de Canto Orfeônico foi dirigido por Lorenzo Fernandez, enquanto Villa-Lobos passava longas temporadas no exterior. Na década de 1940 Heitor conheceu os Estados Unidos da América. Os resultados das suas apresentações foram notórios e sua obra foi bem aceita, fatos que 0 tornaram conhecido e bastante solicitado na América do Norte. Várias orquestras americanas encomendaram a Villa-Lobos novas composições. Além disso, instrumentistas com carreiras consistentes que lá moravam tocaram suas peças. Se no início de sua carreira internacional sua rota era Rio-Paris, na década de 1940 seu eixo passou a ser Rio-Nova lorque, o que tornou o maestro bastante ausente no CNCO e no 
Instituto de Educação (Mariz, 1949). Esses espaços fizeram com que Oscar Lorenzo Fernandez ganhasse notoriedade no campo educacional e se tornasse referência pedagógica do ensino da música no Brasil.

\section{O canto coral nas escolas}

O artigo $O$ canto coral nas escolas aborda mais a esfera pedagógica, quando comparado ao Bases para a organização da música no Brazil. O texto não fica vinculado à estrutura e à gestão da música como o primeiro texto publicado por Oscar na Illustração Musical. Na introdução do segundo artigo, Lorenzo Fernandez se mostra um compositor nacionalista purista. Escreve que somente os povos mais civilizados sabem cantar e, como máxima, afirma que os brasileiros não sabem cantar, que são melancólicos e pessimistas, que "só canta coletivamente no Carnaval; mas antes o não fizesse, pois os cantos desse gênero são, em geral, o que há de mais grotesco" (Fernandez, 1931, p. 67).

Em outras palavras, Lorenzo Fernandez passava para os leitores da revista uma visão comum entre os músicos nacionalistas, pois, para esse grupo de artistas a música modernista deveria buscar sofisticação estética e pedagógica no Brasil. Um processo "que resultasse da incorporação e sublimação da rusticidade do folclore (do povo ingênuo)" (Wisnik, 2001, p. 134) no qual a alta cultura erudita - articulada com o folclore deveria neutralizar "a agitação urbana (o povo deseducado)" (p. 134) a massa deseducada pelo rádio. Nesse contexto a música popular urbana era compreendida como agitadora, sobretudo as composições musicais do carnaval, e as folclóricas como uma rica fonte para os músicos eruditos, pessoas capazes de tratá-las e utilizá-las como um instrumento disciplinador cívico e artístico.

Além disso, o compositor Lorenzo Fernandez, no artigo O canto coral nas escolas, enfatiza os conhecimentos musicais, o entusiasmo e o saber pedagógico como elementos necessários na atuação do professor. Não apresenta um currículo para a formação dos docentes de música, como fez Villa-Lobos (1937) no relatório geral dos serviços realizados de 1932 a 1936 pela Superintendência de Educação Musical e Artística do Distrito Federal. Oscar aponta três itens como condições indispensáveis, diretrizes, para o professor-regente ter competência de liderar os alunos na prática de canto coletivo: sólida cultura musical; entusiasmo e devotamento à arte; capacidade pedagógica.

Oscar Lorenzo Fernandez entende que o professor-regente precisa ter conhecimentos musicais "vastos e profundos" (Fernandez, 1931, p. 67) para poder adentrar na essência de uma obra musical e, para isso, "não basta o conhecimento material da teoria e do solfejo" (p. 67). Assim, segundo sua proposta, o docente de música precisa estudar harmonia, contraponto e fuga. Também considerava desejável que houvesse nos cursos de formação oficinas de composição e ensinamentos filosóficos no campo da estética.

Lorenzo ressalta no artigo que "uma cultura não se improvisa, e é triste entregar a juventude escolar, sempre tão ávida de curiosidade, nas mãos de professores que por deficiência cultural Ihes ministrem noções falsas, senão errôneas, sobre a verdadeira arte" (Fernandez, 1931, p. 67). Vale lembrar que este texto foi publicado na revista Illustração Musical, em 1931, antes da implantação da disciplina Música e Canto Orfeônico nas escolas do Distrito Federal, em 1932, portanto, não se trata de uma crítica ao trabalho de Villa-Lobos no âmbito da formação de professores. 
Lorenzo Fernandez afirma ainda que os regentes dos coros escolares devem ter boas referências musicais, ouvir gravações de peças vocais, instrumentais e sinfônicas de excelência, pois, sendo assim, "pelas leituras e pela audição contínua, formar[iam] uma sólida cultura teórica experimental" (Fernandez, 1931, p. 67). Dessa maneira, Oscar demonstrou que pensava o educador musical como um intelectual da música, com formação artística ampla e profunda. Não esperava formar somente um músico que apenas sabe ler notas e ritmos - solfejar -, um reprodutor do que está escrito nas partituras dos hinários e cancioneiros escolares, e, para tanto, propunha o acesso a gravações de referência para a construção de uma escuta criteriosa.

Entendo que alguns outros aspectos pensados por Lorenzo Fernandez são ideias para uma formação dos professores de música compatíveis com um curso na Escola Nacional de Música, porém utópicos para a proposta que acontecia no Instituto de Educação do Rio de Janeiro, nos âmbitos da UDF, onde parte de suas ideias foram implantadas sob a liderança de Heitor Villa-Lobos. Como explica Diana Gonçalves Vidal (2001), o curso regular de formação do professorado no Instituto era realizado em dois anos: "o primeiro geral; o segundo, comportando a especialização para classes de primeiro, segundo e terceiro graus primários, e quarto e quinto graus" (p. 112). Para quem desejava uma especialização em Música, Desenho, Artes Industriais e Domésticas, Educação Física e Educação e Saúde exigia-se um tempo maior, mais um ano letivo. Contudo, entendo que a formação musical ampla e profunda proposta por Lorenzo Fernandez não poderia ser alcançada nesse curto espaço de tempo, em apenas um ano a mais que era destinado à música.

Sobre o entusiasmo e devotamento à arte escreveu que o docente de música "necessita de comunicar-se diretamente com o aluno através do entusiasmo. Só o entusiasmo é fecundante. É preciso que o professor desperte no aluno, de início, a alegria de cantar" (Fernandez, 1931, p. 67). Também demarcou alguns desafios da profissão, sinalizando para o professor que o seu ofício não é realizado com facilidade, que "a tarefa, no começo, é árdua; mas o professor devotadamente e com fervorosa constância irá transfundindo todo o entusiasmo nas almas juvenis, sempre tão propensas aos nobres atos" (Fernandez, 1931, p. 67). Esta parte do texto parece ser um conselho de Lorenzo Fernandez sobre algo que ele vivenciou musicalmente em sua infância, leu na vida adulta ou observou na experiência de algum professor na escola primária do Instituto de Educação do Rio de Janeiro, porque não há nos seus documentos e nos estudos científicos evidências do músico ter trabalhado diretamente com crianças.

Assim, possivelmente por falta de um conhecimento de causa, por pouca proximidade da realidade com o trabalho com crianças nas escolas de formação geral, o compositor tenha apresentado poucos elementos no tópico que retrata o cotidiano escolar. Ressalto que Oscar Lorenzo Fernandez era um exímio músico, intelectual, poeta, um homem da academia e das artes e, talvez por esse motivo, o seu texto reflita mais suas vivências voltadas para os aspectos artísticos, administrativos da educação e da formação de professores, com pouca ênfase no dia a dia das comunidades escolares.

Nessa perspectiva, Lorenzo Fernandez, ao escrever sobre a capacidade pedagógica, destaca o que parece faltar em seu currículum vitae: a experiência de trabalhar com crianças. Segundo os seus pressupostos, "o contínuo contato com a alma 
infantil fará com que, compreendendo-a, nos tornaremos compreensíveis" (Fernandez, 1931, p. 67), um preâmbulo para abordar a questão da transposição didática, com as seguintes palavras:

O professor deve explanar sempre as ideias com clareza e simplicidade. (A erudição melhor fica numa academia do que numa sala de infantil). Sendo simples deve evitar, no entanto, a monotonia: ora transformando certos elementos teóricos em jogos infantis; ora amenizando a aula com histórias adequadas e anedotas relativas à música e aos músicos. (Fernandez, 1931, p. 67)

No artigo Lorenzo Fernandez não menciona métodos específicos, relacionados ao ensino da música, que eram conhecidos no Brasil. Contudo, faz considerações sobre explorações sonoras como exercícios para se obter, de maneira sistemática, o aprimoramento da afinação. Sugere exercícios rítmicos com marchas, enfatizando o primeiro tempo de cada compasso e práticas de ginásticas para o aluno incorporar outros ritmos. Num segundo momento, "quando o aluno já estiver bem familiarizado com o sentido nas suas relações fortes e fracas" (Fernandez, 1931, p. 68), indica o trabalho com marchas rítmicas alternadas com lições de entoação e, por último, num terceiro momento, sugere o canto de frases musicais completas simultaneamente com a ginástica rítmica. Portanto, mesmo sem indicar o método do educador musical suíço Émile JaquesDalcroze, demonstra conhecer os princípios do ensino da música por meio da eurritmia ${ }^{2}$. Possivelmente, não indicava o modelo suíço por falta de familiaridade com essas metodologias para a musicalização de crianças, que ainda estavam em processo de divulgação no Brasil.

O texto de Lorenzo Fernandez que apresenta o canto coral nas escolas como uma estratégia de musicalização é um marco na educação brasileira, mesmo que apenas alguns aspectos tenham ganhado vida na prática no decorrer de décadas do século 20 . Infelizmente Oscar não viveu para ver algumas das conquistas dos projetos desse grupo dos músicos nacionalistas que transitavam no Instituto de Educação. O músico faleceu aos cinquenta anos com problemas cardíacos.

Os registros do obituário de Lorenzo Fernandez demonstram como a sociedade artística da capital da República ficou surpreendida com o abreviamento de sua vida, em 27 de agosto de 1948, quando sofreu um "edema agudo de pulmão, com hipertensão e nefro esclerose." 3 Seus primeiros problemas cardíacos foram identificados pelos médicos em 1945, quando concluiu sua primeira sinfonia.

\section{Considerações finais}

Depreendo que os ideais de Lorenzo Fernandez para a música na educação brasileira, publicados na revista Illustração Musical, tinham como base a formação de professores por meio de cursos especializados com consistente conhecimento musical e pedagógico, uma proposta que dependia dos investimentos do governo. Neste sentido,

\footnotetext{
${ }^{2}$ Neste caso, entende-se eurritmia como exercícios para o desenvolvimento do sentido métrico e rítmico por meio dos matizes de movimentos corporais em relação aos movimentos sonoros (Fernandino, 2008).

${ }^{3}$ Certidão de Óbito, $2^{\text {a }}$ Circunscrição - $1^{\mathrm{a}}$ zona - Freguesia de Sacramento e São José - Comarca da Capital. (Acervo Histórico da Biblioteca do Conservatório Brasileiro de Música - Centro Universitário). Hist. Educ. (Online) Porto Alegre v. 20 ก. 49 Maio/ago., 2016 p. $227-238$
} 
para a concretização de suas ideias, o Instituto de Educação do Rio de Janeiro, que esteva vinculado à Universidade do Distrito Federal - UDF -, foi importante para subsidiar a formação dos docentes de música e promover a articulação desses com a realidade da escola pública. Um lugar diferente do previsto em seus textos, que vislumbravam o Instituto Nacional de Música como a instituição ideal para a formação dos docentes de música.

No que se refere às redes de cooperação percebe-se que, entre Lorenzo Fernandez e Heitor Villa-Lobos, havia uma relação de parceria em prol da música nacionalista e da educação musical brasileira. Por um lado, Oscar era o intelectual que elaborava concepções e estruturas para o avanço da música nas escolas e, por outro lado, Heitor era o artista que conseguia notoriedade e trânsito entre os gestores da educação pública e governantes da Era Vargas para efetivação das propostas musicais e pedagógicas.

\section{Referências}

ANDRADE, Mário Raul de Moraes. Lourenço Fernandez. Diário de São Paulo, 26 de janeiro de 1934. (Acervo Histórico da Biblioteca do Conservatório Brasileiro de Música Centro Universitário.)

BASTOS, Maria Helena Camara. Impressos e cultura escolar: percursos da pesquisa sobre a imprensa estudantil no brasil. In: HERNANDEZ DIAS, José Maria (org.). La prensa pedagógica de los escolares y estudiantes: su contribuición al patrimonio histórico educativo. Salamanca: Universidad Salamanca, 2015, v. 1, p. 21-43.

BRASIL. Decreto-lei n. 4.993, de 26 de novembro de 1942. Estabelece o Conservatório Nacional de Canto Orfeônico. Disponível em <http://www.senado.gov.br>. Acesso em 8 mar. 2015.

CATANI, Denice Barbara. A imprensa periódica educacional e o estudo do campo educacional. In: Educação e Filosofia, Minas Gerais, v. 10, n. 20, 1996, p. 115-130.

FERNANDEZ, Oscar Lorenzo. Bases para a organização da música no Brazil. Ilustração Musical, Rio de Janeiro, ano 1, n. 3, 1930.

FERNANDEZ, Oscar Lorenzo. O canto coral nas escolas. Illustração Musical, Rio de Janeiro, ano 2, n. 3, 1931.

FERNANDEZ, Oscar Lorenzo. O nosso programa. Ilustração Musical, Rio de Janeiro, ano 1, n. 1, 1930, p. 1.

CORREAA, Sérgio Nepomuceno Alvim. Lorenzo Fernandez: catálogo geral de obras. Rio de Janeiro: Rio Arte, 1992.

FERNANDINO, Jussara Rodrigues. Música e cena: uma proposta de delineamento da musicalidade no teatro. Belo Horizonte: UFMG, 2008. 149f. Dissertação (mestrado em Artes). Escola de Belas Artes, Universidade Federal de Minas Gerais.

MARIZ, Vasco. Heitor Villa-Lobos: compositor brasileiro. Rio de Janeiro: Serviço de Publicações/Ministério das Relações Exteriores/Divisão Cultural, 1949.

MENDONÇA, Ana Waleska Pollo Campos. Anísio Teixeira e a universidade de educação. Rio de Janeiro: Uerj, 2002.

MONTI, Ednardo Monteiro Gonzaga. Canto orfeônico: a linguagem musical em vozes políticas e educativas. Revista Teias (Online), v. 12, 2001, p. 179-195. 
MONTI, Ednardo Monteiro Gonzaga. Polifonias políticas, identitárias e pedagógicas: VillaLobos no Instituto de Educação do Rio de Janeiro na Era Vargas. Rio de Janeiro: Uerj, 2015. 297f. Tese (doutorado em Educação). Universidade do Estado do Rio de Janeiro.

PÁDUA, Mônica Pedrosa de. Imagens de brasilidade nas canções de câmara de Lorenzo Fernandez: uma abordagem semiológica das articulações entre música e imagem. Belo Horizonte: UFMG, 2009. 275f. Tese (doutorado em Estudos Literários). Faculdade de Letras, Universidade Federal de Minas Gerais.

SIQUEIRA, Baptista. Do conservatório à escola de música. Ensaio Histórico, Rio de Janeiro: UFRJ, 1972.

VIDAL, Diana Gonçalves. O exercício disciplinado do olhar: livros, leituras e práticas de formação docente no Instituto de Educação do Distrito Federal (1932-1937). Bragança Paulista: USF, 2001.

VIEIRA, Carlos Eduardo; RABALLO, Roberlayne de Oliveira Borges. A escrita da história da educação no Brasil: formando professores através de noções de história. CONGRESSO LUSO-BRASILEIRO DE HISTÓRIA DA EDUCAÇÃO, 8, 2010. Anais ... São Luís: UFMA, 2010.

VILLA-LOBOS, Heitor. Educação musical. Boletim Latino Americano de Música. Rio de Janeiro: Imprensa Nacional, ano 4, v. 6, 1946.

VILLA-LOBOS, Heitor. Sema: relatório geral dos serviços realizados de 1932 a 1936. Tomo III. Montevidéo, 1937.

WISNIK, José Miguel. Nacionalismo musical. In: SQUEFF, Enio; WISNIK, José Miguel. O nacional e o popular na cultura brasileira - música. São Paulo: Brasiliense, 2001.

EDNARDO MONTEIRO GONZAGA DO MONTI é professor na Universidade Federal do Piauí e doutor em Educação pela Universidade do Estado do Rio de Janeiro.

Endereço: Universidade Federal do Piauí, Centro de Ciências da Educação, Coordenação de Música - Avenida Universitária, Ininga - 64049-550 - Teresina - PI - Brasil.

E-mail: ednardomonti@gmail.com.

Recebido em 7 de janeiro de 2016.

Aceito em 30 de março de 2016. 